Estudios Románicos, Volumen 28, 2019, pp. 295-306

ISSN: 0210-491

eISSN: 1989-614X

DOI: https://doi.org/10.6018/ER/377351

\title{
NARRATIVA CRIMINAL ESCRITA POR MULLERES: CINCO NOVELAS GALEGAS
}

(Criminal Fiction written by women: five Galician novels)

\author{
Teresa López* \\ Universidade da Coruña
}

\begin{abstract}
Crime in Compostela was published in 1984 by Carlos G. Reigosa, considered the inaugural work of the criminal novel in Galician. Despite the relative editorial success of the genre, few women writers will cultivate it: the first, Laura Caveiro, author of Polas inmensas e alleas fortunas (1995). This paper reviews the later contributions of Galician women writers to criminal narrative-Matei un home (2003) de An Alfaya, Sete caveiras (2014) de Elena Gallego, O faro escuro (2015) de María López Sández e Compostela Noire (2016) de Blanca Riestra-, to place them in relation to the clichés of the genre and with the definition of archetypes of female (and male) characters.
\end{abstract}

Keywords: Galician Criminal Narrative; Galician Women Narrators; An Alfaya; Elena Gallego; María López Sández; Blanca Riestra.

Resumo: En 1984 foi publicada Crime en Compostela, de Carlos G. Reigosa, considerada a obra inaugural da novela criminal en galego. A pesar do relativo éxito editorial do xénero, poucas escritoras o frecuentarán: a primeira, Laura Caveiro, autora de Polas inmensas e alleas fortunas (1995). Neste traballo revísanse as achegas posteriores das escritoras galegas á narrativa criminal-Matei un home (2003) de An Alfaya, Sete caveiras (2014) de Elena Gallego, O faro escuro (2015) de María López Sández e Compostela Noire (2016) de Blanca Riestra-, para as situar en relación cos clixés do xénero e coa definición de arquetipos de personaxes femeninos (e masculinos).

Palabras chave: Narrativa criminal; Narradoras galegas; An Alfaya; Elena Gallego; María López Sández; Blanca Riestra.

\footnotetext{
* Enderezo para correspondencia: Teresa López. Departamento de Letras. Facultade de Filoloxía. Universidade da Coruña. Rúa Lisboa 7.15008 A Coruña (t.lopez@udc.gal).
} 


\section{Novela criminal galega}

1984 é considerado o ano do nacemento da narrativa criminal ${ }^{1}$ en Galiza, por ser cando se publicou Crime en Compostela, de Carlos G. Reigosa, novela galardoada co I Premio Xerais de novela. Aínda que poidan ser sinalados algúns precedentes, certamente problemáticos (González Gómez 2002: 76-77), o nacemento deste xénero en lingua galega é serodio, como tamén o foi no conxunto da península ibérica, e ás causas socioculturais e políticas que explican o seu retraso no estado (Colmeiro 1994, Resina 1997), deben ser sumadas as sociolingüísticas no caso galego.

A novela criminal surxe no contexto da diversificación e da expansión da narrativa galega que se produce no posfranquismo, en que aparecen modalidades (novela de aventuras, ficción científica, relato erótico etc.) que noutros ámbitos culturais tiñan unha tradición de décadas e se caracterizaban por un consumo masivo. Entre os paradoxos deste proceso debe ser destacado que, xunto coa aparición da narrativa de xénero, se desenvolve de forma paralela a súa parodia (González-Millán 1994).

Crime en Compostela acabou por se converter nun best-seller: a finais de 1992 vendera un total de 27.000 exemplares, unha cifra moi alta para a edición en lingua galega deses anos. Porén, o éxito de público non foi acompañado pola unanimidade da crítica: a obra tivo afervoados defensores mais tamén foi considerada como un produto falido, que non respondía ás necesidades de renovación narrativa desde parámetros identitarios, ou como un mero exercicio formal (González-Millán 1996: 296-300).

A aposta institucional por unha narrativa de xénero que respondese ás demandas dun novo público lector -que existía, como probaba o éxito de vendas da obra de Reigosa- e, simultaneamente, contribuíse a consolidalo e alargalo, vaise pór de manifesto coa apertura de coleccións editorais específicas e coa dotación de premios singulares. No caso da novela criminal, Xerais inaugura a serie Negra en 1988, Edicións do Cumio abre a colección Cómplice en 1989, e neste mesmo ano o consorcio Compostela Cultural crea o Premio Semana Negra de Novela Curta que gaña Roque Morteiro (Xelís de Toro) con Tres cordas e un corazón. A crítica literaria acompañou a aparición do xénero, con publicacións monográficas como o dossier da revista Anima+l editado en 1991 (González Gómez 2002, Vilavedra 2010).

Nos anos seguintes á publicación de Crime en Compostela, crecerá o número de autores que se incorporen, ás veces de forma puntual, ao cultivo da narrativa criminal: Román Raña, Aníbal Malvar, Manuel Forcadela, Ramiro Fonte, Ramón Caride, Suso de Toro etc. (Dopico 2012). Se a década de 80 fora a do nacemento do xénero, a seguinte podería ser considerada a de eclosión, polo incremento de obras e a diversificación de modelos narrativos, coa aparición do policial rural ou da confluencia entre narrativa histórica e detectivesca ${ }^{2}$. Algunhas novelas recibirán importantes premios, un feito que mostra o temperán interese pola canonización do xénero (Vilavedra 2010: 113):

\footnotetext{
1 Utilizamos esta denominación por considerala máis axustada por abranxente, aínda que a crítica galega ten usado de forma preferente os cualificativos "policial" e "negra" e, en menor medida, "detectivesca".

2 O xénero criminal foi tamén un molde utilizado na narrativa xuvenil desde a década dos oitenta, como mostran A chave das noces (1987) de Xabier P. Docampo e Investigación 091 (1989) de Pepe Carballude.
} 
Raña, o Blanco Amor por O crime da rúa da Moeda Vella, en 1989; Malvar, o máis destacado narrador noir dos noventa, o García Barros por A man dereita en 1994 e, no ano seguinte, o Xerais por Unha noite con Carla.

A viraxe do século vai traer novos autores, entre eles tres que se converterán en referencias na narrativa criminal: Miguel Anxo Fernández, que inaugura con Un nicho para Marilyn (2003) a saga do detective Frank Soutelo; Diego Ameixeiras, o máis constante, plural e interesante cultor actual do xénero, que debuta con Baixo mínimos (2004), e Domingo Villar, autor dos best-sellers Ollos de auga (2006) e A praia dos afogados (2009). Na década presente o xénero continúa a gozar do favor lector e editorial -a pesar da desaparición das coleccións específicas que o acollían-, como pon de manifesto o éxito de autores como os citados Villar e Ameixeiras, a incorporación de nomes ao elenco autorial, a publicación de novas obras e a creación de sagas detectivescas, como a do inspector Carlos Manso, protagonista d'A ira dos mansos (2016) de Manuel Esteban, Premio Xerais, e d'O meu nome é ninguén (2018).

\section{Narrativa criminal escrita por mulleres}

Once anos despois da edición de Crime en Compostela, a colección Negra de Xerais publica a primeira novela criminal escrita por unha muller, Polas inmensas e alleas fortunas (1995) de Laura Caveiro, que foi definida por Xesús González Gómez como "unha excelente parodia, no sentido bakhtiniano do termo, que me parece foi mal lida no seu día" (González Gómez 2002: 78).

De certo, a novela debe ser entendida como unha reacción á proliferación do modelo hard-boiled na narrativa criminal - de autoría masculina- que inundaba as súas páxinas de mulleres enigmáticas e fatais, xornalistas, detectives privados, policías corruptos, atmosferas grises etc. Consoante con esta opción, as mulleres representadas nas obras correspondían maioritariamente "ó prototipo de "Glamour girl", partenaire do "gánster" no mellor estilo Jean Harlow: loira platino en bata, fumando e bebendo a calquera hora, obxectualizada polo seu protector" (Gaspar 1994: 114). Polas inmensas $e$ alleas fortunas levará deliberadamente ao límite este modelo. Arredor do protagonista, o detective Tom Vas, misóxino e violento, xiran unha serie de personaxes femeninos estereotipados: a súa ex-parella Patricia; unha secretaria cousificada até o extremo de carecer de nome -é reiteradamente denominada como "o bombón"-; Victoria Ferreira, unha clienta con boa posición social e económica que busca a súa axuda; Susana, unha adolescente imprevisíbel e fráxil. Tal e como indica $\mathrm{M}^{\mathrm{a}}$ Xesús Lama (2015), son as relacións entre homes e mulleres o tema central da crítica social da obra e a intriga é un mero pretexto para facer interaccionar os personaxes, e pór así de relevo o modelo de masculinidade agresiva que o protagonista representa e os valores que rexen unha sociedade patriarcal (e corrupta) como a retratada na novela. En suma, Laura Caveiro propón unha relectura do harboiled desde unha perspectiva feminista.

Desde a publicación de Polas inmensas e alleas fortunas moi poucas autoras escribiron novela criminal, como poucas, en xeral, cultivaron a narrativa de xénero -coa excepción da narrativa infantil e xuvenil, de podermos considerala propiamente un 
xénero. Este feito non pode entenderse sen considerar o desenvolvemento fragmentado da narrativa de autoría feminina, que non acadaría unha relativa normalización até meados da primeira década do século XXI, coa incorporación de novas narradoras -especialmente as nadas na década de 70-, á creación de novos modelos autoriais e o paseniño recoñecemento institucional (González Fernández 2009: 27-61; Vilavedra 2010: 303-319). É precisamente nesta altura, dez anos despois da novela de Caveiro, cando An Alfaya publica Matei un home (2005). E haberá que agardar case outra década, coincidindo cun novo boom da novela criminal, para contar de novo con achegas de narradoras a este xénero3: Sete caveiras (2014) de Elena Gallego, O faro escuro (2015) de María López Sández e Noire Compostela (2016) de Blanca Riestra4.

Destas catro obras, tres concorreron ao premio de novela por entregas convocado por La Voz de Galicia: as novelas de Alfaya e López Sández foron finalistas, e a de Riestra gañouno. Este certame, cuxa última edición foi en 2017, fixaba unhas estritas normas para os orixinais (debían ter 31 capítulos de 3.500 caracteres), prevía a publicación da obra vencedora no xornal convocante no mes de agosto - nas edicións dixital e impresa-, a razón de capítulo por día, e contaba cunha dotación económica relevante $\left(10.000 €\right.$ nas últimas convocatorias) ${ }^{5}$.

Dadas as condicións estabelecidas nas bases do premio, parece probábel que as novelas citadas fosen escritas ad hoc, de forma que no cultivo do xénero criminal por parte destas autoras pesaría a adecuación deste modelo narrativo á novela por entregas: un xénero altamente codificado, recoñecíbel para un público masivo, e co suspense como unha das súas chaves. Se nas décadas finais da pasada centuria e na viraxe do século as narradoras mostraran ante todo a vontade de definir os seus persoais proxectos literarios, á marxe da narrativa de xénero (Vilavedra 2010), o (moderado) interese pola narrativa criminal faría parte da definición de novos modelos autoriais, en que influirían factores como a vontade de chegar a un público máis amplo, de visibilizar a actividade literaria, de procurar non só (re)coñecemento institucional mais tamén social, e de contribuír ao desenvolvemento dun xénero de consumo, mesmo desde a limitación que impón seren todas autoras dunha única narración no xénero.

Matei un home (2005) foi publicada dous anos despois de concorrer e quedar finalista no premio de La Voz de Galicia -que An Alfaya gañaría en 2010 por Vidas cruzadas-, e logo de obter o premio de novela curta Xulián Magariños, promovido polo Concello de Negreira. No momento da publicación, a autora, nada en 1964, era coñecida principalmente pola súa obra dirixida ao público infantil e xuvenil.

3 Con este artigo xa entregado, foron publicadas as novelas Beleza vermella de Arantza Portabales e Infamia de Ledicia Costas.

4 A base de datos MUNCE (Mujeres y novela criminal en España desde 1975), recolle as obras de Caveiro, Gallego e López Sández. Das 78 autoras rexistradas, só catro son escritoras en lingua galega, as tres citadas e $\mathbf{M}^{\mathrm{a}}$ Xosé Queizán, incluída por Meu pai vaite matar (2011). Aínda que esta novela ten como protagonista a Diana, unha policía, e utiliza algúns elementos do xénero criminal, ten tamén de ingredientes da novela de aventuras, da literatura de viaxes e da novela de tese, e o seu eixo central é a indagación na memoria familiar da protagonista e na súa propia identidade, razóns todas polas que decidimos excluíla do corpus abordado neste artigo.

5 Segundo a última onda de 2018 do 'Estudio General de Medios', La Voz de Galicia é lida por 529.000 persoas/día (http://reporting.aimc.es/index.html\#/main/diarios; último acceso: 1/4/2019). En https://www.lavozdegalicia.es/default/2017/05/22/00171495442774322373207/Fichero/novelaentregas1.pdf (último acceso: 1/4/2019) poden consultarse as bases da derradeira edición do premio. 
A novela narra a investigación da morte de Laura Solves polos policías Montes e Torres, con Amadeo Foz, mozo de Laura e ex-convicto, e Marcial Pena, unha antiga relación da vítima, como principais sospeitosos do crime. A narración articúlase como unha combinación de whodunit -que xoga coa idea do falso culpábel encarnado en Amadeo-, procedemento policial e introspección psicolóxica.

Amadeo é o protagonista da narración, e a definición da súas diferentes funcións narrativas serve para dosificar a intriga: parella da vítima, asasino confeso, presunto culpábel da morte de Laura. No achegamento ao personaxe, a introspección psicolóxica serve para facer autoanálise da súa condición de sospeitoso e das consecuencias de ser considerado responsábel do asasinato, e para repasar a súa historia persoal e a súa relación de parella coa vítima.

Laura é evocada fragmentariamente en sucesivas analepses por Amadeo, de forma que é o seu punto de vista o que determina o deseño da personaxe. É descrita fisicamente a partir dun retrato fotográfico como unha beleza antiga e sedutora ${ }^{6}$, é a muller compasiva e comprensiva que ten o poder de mudar a visión do mundo de Amadeo (Alfaya 2005: 55), que co seu amor o redime da culpa que arrastra polo asasinato do pai, un xuíz respectado, de quen descobre que é un pederasta. Mais a evocación de Amadeo presenta unha Laura que non só é o seu sostén emocional: el mora na súa casa e depende economicamente dela. A coincidencia nominal entre Laura e a nai de Amadeo - de quen está distanciado-subliña a función maternal que aquela desempeña, como tamén o feito de que o protagonista volva a achegarse á nai logo de ser exculpado da morte da súa parella.

A condición de ser pasivo de Amadeo, dependente de Laura, ten o seu reverso na situación que dá orixe á súa relación, que comeza de forma improbábel co torpe e falido atraco de Amadeo a Laura, un episodio inicial que os protagonistas recrean utilizando a simulación da violencia como estímulo erótico. A suposta condición criminal de Amadeo, que dá título á obra ("Matei un home"), está contrarrestada na afirmación de Laura ("Ti non es un asasino"), que exculpa a Amadeo. Unha exculpación que repetirá Encarna, viciña da parella, ao afirmar: "Matou por xustiza".

Se Laura é a vítima, as restantes personaxes femininas da novela desempeñan roles secundarios, esterotipados e vinculados ao espazo da domesticidade: Encarna, a veciña viúva e entremetida; a nai de Torres, que vive co fillo e cuida del como se aínda fose un neno; outras nais e esposas apenas mencionadas e de nula relevancia narrativa...

Por razóns dispares, en Polas inmensas e alleas fortunas e Matei un home a autoría feminina non trae unha renovación dos clixés do xénero nin a subversión dos estereotipos femeninos: na obra de Caveiro, porque a súa pretensión é exacerbar ambos, a través da parodia, para pór de manifesto a condición do hardboiled de vehículo para a afirmación dunha ideoloxía patriarcal; na obra de Alfaya, porque a combinación de modelos da novela criminal non supón a superación de ningún dos estereotipos do xénero.

Só na década seguinte as novelas criminais incoporarán, como un elemento de reno-

$6 \quad$ O nome, a función da rememoración na construción da personaxe, a presenza do retrato e a importancia da vivenda da vítima, entre outros aspectos, evocan Laura (1942), a novela de Vera Caspary levada ao cinema por Otto Preminger en 1944. 
vación, novos roles para os personaxes femeninos nas obras das narradoras e nas novas achegas de autores de referencia, como Diego Ameixeiras (por exemplo, en Matarte lentamente, de 2013).

\section{A década actual: tres novelistas, tres novelas}

Sete caveiras (2014) de Elena Gallego, O faro escuro (2015) de María López Sández e Noire Compostela (2016) de Blanca Riestra son tres novelas que, desde presupostos diversos, van introducir innovacións na narrativa criminal galega. As súas autoras, nadas en volta de 1970 -Elena Gallego naceu en 1969, Blanca Riestra en 1970 e María López Sández en 1973-, teñen unha traxectoria previa como narradoras: Elena Gallego é autora da saga xuvenil de fantasía Dragal, iniciada en 2010 e traducida a varias linguas; Blanca Riestra ten unha sólida e premiada produción narrativa en español -inaugurada en 1996 con Anatol y dos más-, e María López Sández recibira o premio de narrativa breve Repsol pola súa primeira novela, A forma das nubes (2012).

A primeira destas novelas en ser publicada, Sete caveiras, acadou en 2018 a súa sexta edición, un dato que a presenta como un relativo éxito de vendas. Á súa aceptación no mercado probabelmente non é allea a utilización de mecanismos de promoción propios da literatura de masas: a novela dispón de páxina en Facebook, de páxina web e como material promocional foi elaborado un booktrailer. A difusión da obra a través da Internet e das redes sociais foi en boa medida responsabilidade da propia autora, xornalista de profesión, que partía da súa experiencia previa na promoción da serie Dragal, orixe de diversos materiais multimedia e dun proxecto didáctico para as aulas de secundaria. Desta forma, a opción pola narrativa de xénero vai alén do molde narrativo: implica a asunción por parte da autora da novela como produto de consumo cultural de masas.

Sete caveiras narra como Marta Vilas, xornalista de sucesos desterrada á sección de suplementos por discrepancias coas decisións periodísticas do redactor-xefe, encontra casualmente un cadáver na ría de Vigo mentres tiraba fotografías. Xunto ao corpo aparece un bonequiño dos Clics de Famóbil. É o primeiro dunha serie de mortos que aparecerán ao longo da semana, en diferentes localizacións da ría, acompañados de novos bonecos que identifican diferentes profesións. Marta recupera o seu anterior posto e leva adiante unha investigación paralela á oficial, a cargo da Garda Civil, na que descubrirá os vínculos entre os asasinados, todos colegas de adolescencia do seu xefe no Vigo dos anos 80 e responsábeis da violación grupal dunha adolescente, como final dunha noite de festa e drogas no ano 1986, nun brutal rito de paso á idade adulta. A rapaciña suicídase pouco despois e o irmán pequeno, que a acompañaba nesa noite e non a puidera defender, vivirá atormentado pola culpa até que decide vingarse.

A novela homenaxea Dez negriños (Ten little niggers, 1939), célebre obra de Agatha Christie, autora mencionada na narración como lectura de adolescencia da protagonista (Gallego 2014: 23). As figuriñas, que aquí aparecen e alí desaparecían, e unha canción ("Siete calaveras" do grupo La Frontera) son os principais acenos á novela inglesa. Sete caveiras comparte tamén coa obra de Christie un motivo argumental relevante: as vítimas sono porque foran tamén culpábeis, responsábeis dun crime que quedara sen 
castigar. Tomando como referencia á famosa escritora, o texto inscríbese na tradición da novela-enigma e do whodunit .

Outros aspectos vinculan a obra de Gallego coa tradición da novela negra galega: o escenario urbano de Vigo, visto da perspectiva da fronte marítima da cidade -como nas novelas de Domingo Villar-, as referencias ao narcotráfico, e o retrato da cidade na década de 80 , o tempo ao que conduce a investigación, os anos da movida, da reconversión naval e do consumo masivo de drogas.

Porén, a utilización do suspense (a intriga narrativa descansa no que está por acontecer), os asasinatos en serie e certos aspectos da construción da personaxe protagonista como heroína de acción colocan o texto no ámbito do thriller de inspiración audiovisual.

A principal innovación na narrativa criminal galega de Sete caveiras é a introdución dunha investigadora como protagonista absoluta da narración ${ }^{8}$. De feito, o hiperprotagonismo de Marta Vilas contrasta coa escasa presenza de personaxes femininas, todas incidentais na trama, e con posicións subalternas -como a propia Marta- no mundo laboral: Ana, a telefonista do xornal, a súa ex-compañeira de sección, Cristina, ou a enfermeira sen nome que a atende cando chama á consulta dun psiquiatra.

O personaxe de Marta responde aos novos estereotipos do investigador/a na narrativa criminal, que incorpora aspectos da cotidianeidade e da súa intimidade: os seus hábitos domésticos, as súas afeccións, a súa relación de parella-con algunhas tensións pola súa dedicación ao traballo-, a frecuentación do bar de Paco -unha referencia que serve para parodiar as devocións e as rarezas gastronómicas de moitos detectives post-Carvalho-e, como no caso de moitas investigadoras novelescas, a súa cuestión pendente coa maternidade (Losada 2015: 12). Mais Marta responde tamén ao prototipo de heroína solitaria e decidida, que arrisca a súa integridade física nun encontro persoal co presunto asasino, cun carácter independente e cun criterio propio, adoptando unha posición de outsider, que feminiza os estereotipos masculinos do xénero criminal, mesmo na incorporación de leves equívocos sexuais na súa relación con outros personaxes.

Marta é tamén a encarnación dunha idea: a do xornalismo que se guía por un código ético, fronte á súa desvirtuación polas complicidades co poder e ás concesións ao morbo dos empresarios xornalísticos. O papel da prensa reivíndicase a través da súa función na propia trama narrativa, pois, alén da intuición da protagonista, é unha pesquisa de hemeroteca a que resulta decisiva para resolver os asasinatos.

Alfredo Miranda, o asasino, é presentado tamén como vítima do trauma causado pola violación e a morte da súa irmá. Un trauma que leva marcado fisicamente na cicatriz do rostro, lembranza do acontecido naquela noite afastada no tempo. As vítimas son tamén culpábeis, responsábeis impunes da brutal agresión. Se impune quedara o seu crime, impunes quedarán as súas mortes: non hai probas e non pode haber conde-

7 O whodunit (en tradución literal, 'quen o fixo') desenvolve unha trama, a modo de quebracabezas, centrada en averiguar a identidade do/a criminal a partir dun grupo pechado de sospeitosos. Entre as obras que mellor o representan, figura a novela citada de Agatha Christie.

8 Vén a coincidir cun desenvolvemento similar no ámbito do audiovisual galego: en 2014, a TVG estreou Serramoura, protagonizada por unha sarxento da Garda Civil, Marga Neira. 
na. Fronte á memoria permanente do acontecido nesa noite de agosto que acompaña a Alfredo, Pablo Curuxeiras, o xefe de Marta, un dos responsábeis do crime, só lembra o acontecido ante a angustia por unha morte inminente, un esquecemento que representa a normalización social e persoal da violencia sexual contra as mulleres.

Marta descobre como o sistema policial e xudicial protexera os criminais e permitira que o delito quedase sen resolver, unha protección que se prolonga na actualidade coa ocultación da natureza dos crimes, en que colaboran os medios de comunicación, e que continuará logo da resolución do caso, ante a imposibilidade de facer xustiza ou de poder contar o que realmente aconteceu. A decisión do personaxe de abandonar unha profesión na que deixa de crer abre paso a un final metaficcional un tanto forzado, xustificando a conversión dos bonecos en personaxes de novela.

Sete caveiras propón un prototipo de investigadora independente e intuitiva, que se move nas marxes, unha aproximación á figura do asasino xusticeiro, que o presenta tamén como vítima, e coloca no foco narrativo a impunidade da violencia sexual contra as mulleres.

O faro escuro (2015) de María López Sández narra a desaparición e o secuestro de Catalina Moscoso, unha xornalista galega que triunfou en Madrid, tras o seu regreso a Galiza para realizar unha reportaxe con motivo do aniversario dun accidente aéreo a que ela mesma sobrevivira. O caso é encargado á inspectora Elisa Neira, que coñecera Catalina nos inicios da súa carreira profesional, cando investigaba varios asasinatos de mulleres na Costa da Morte. Os capítulos da novela alternan a investigación policial e o relato do cativerio de Catalina, e o suspense radica en saber se a inspectora chegará a tempo de salvar a vítima, cunha construción narrativa inspirada na montaxe en paralelo de ascendencia cinematográfica, que alterna a focalización narrativa na investigadora, na vítima e no secuestrador.

O faro escuro podería ser definido como un thriller policial de filiación audiovisual que propón unha feminización dos estereotipos da narrativa criminal. Dous son os personaxes principais: Elisa, a primeira investigadora dos corpos de seguridade estatais da narrativa criminal galega, e Catalina, unha profesional de éxito. Ambas comparten a súa condición de mulleres profesionais mais representan opcións contrapostas na súa dedicación laboral e na súa vida persoal. Catalina é o prototipo de triunfadora ambiciosa, que coloca a súa profesión por riba de todo, Elisa é o exemplo de muller que, a pesar das súas capacidades, se (auto)limita profesionalmente, por razóns emocionais e persoais. Catalina destaca pola súa beleza excepcional e polo seu carácter autosuficiente, está en proceso de divorcio e non é nai. A súa exposición pública vai facer dela tamén unha vítima ocasional de acoso. Elisa ten un fillo menor con parálise ao seu cargo: o seu espazo doméstico, coas súas rotinas e ausencias, está presente na novela, para subliñar os equilibrios que debe facer para conciliar a súa profesión coa atención ao neno, para a que dispón do apoio da rede familiar (a súa irmá pequena, freelance) e dunha coidadora, por tanto, un entorno feminino. Frente á indiferenza que Catalina parece sentir ante os demais, Elisa leva a súa empatía ao extremo de experimentar fisicamente o sufrimento que supón ás vítimas. Na construción antitética de ambas personaxes, outro trazo que opón Elisa e Catalina é o apego 
ao seu lugar de orixe: o arraigo de Elisa e desarraigo de Catalina, que só regresa a Galiza por razóns profesionais.

O cativerio de Catalina, indefensa no zulo que lle preparou o seu secuestrador, resaltará a súa vulnerabilidade: agora será Cati, e ocuparase non só da súa propia supervivencia, senón de atender o cachorro que o secuestrador lle fai chegar. Esta circunstancia marcará unha nova dimensión na personaxe, afectiva e sentimental, mais tamén subliñará a súa condición de supervivente por riba de todo. Mentres, a investigación levará a Elisa a converterse en improbábel heroína de acción, que segue os seus instintos e prescinde dos protocolos, até o punto de pór en risco a súa vida.

O triángulo protagonista complétase co secuestrador, Roberto Leis Fontán, un ser solitario, que vive isolado na illa en que é fareiro, voyeur e calculador, con trazos de fetichismo patolóxico (fantasea con conservar a cabeleira da víctima unha vez morta), que falece nun accidente fortuíto, cando abandona a persecución de Catalina para regresar ao faro e amañar unha avaría que evite o choque contra os cantís dun barco mercante. Paradoxalmente, o secuestrador morre vítima do seu compromiso cos seus deberes profesionais e como resultado do azar.

O secuestrador é presentado tamén como unha vítima marcada polo trauma de presenciar o falecemento da nai e da irmá pequena, unha bebé, no accidente aéreo ao que Catalina e el sobreviviran e, sobre todo, por ver como ela tivera unha improbábel posibilidade de salvar a bebé. A súa vinganza só se fai real por azar, cando a xornalista se presenta na súa casa para o entrevistar para unha reportaxe conmemorativa da catástrofe aérea. $\mathrm{O}$ secuestro culminaría cunha caza humana que pretendería reproducir a situación orixe do trauma e ofrecer á xornalista unha posibilidade de salvación/redención, póndoa a proba para ver se tentaba salvar o cachorro. $\mathrm{Na}$ actitude do secuestrador está presente o trauma, mais tamén a culpa por non ter respondido ao modelo masculino de protector e salvador. E, en certa forma, Catalina é castigada por non cumprir co estereotipo feminino do sacrificio (real ou metafórico) da propia vida pola de outras persoas.

$\mathrm{Na}$ súa feminización do xénero criminal, $O$ faro escuro introduce figuras femininas que ocupan posicións de relevancia profesional e social e que, mesmo de forma esquemática e un tanto extrema, representan diferentes modelos ante a maternidade, os coidados e a vida profesional.

Noire Compostela (2016) de Blanca Riestra sinala, no seu título, á obra que abrira o xénero criminal en Galiza (Crime en Compostela de Carlos Reigosa), e apunta á redefinición da imaxe da cidade compostelá na tradición literaria galega, para destacar a súa dimensión de espazo sórdido e convidar, para alén do topicamente realista, a indagar na cidade oculta, nos segredos presentes e pasados de todas as Compostelas negras. Neste sentido, vén continuar o tratamento do espazo urbano compostelán das novelas de Aníbal Malvar ou de Diego Ameixeiras.

Porén, a novela non se limita a utilizar o modelo do noire: é unha narración híbrida que xoga con códigos do relato fantástico, de misterio, de terror, do gore e mesmo da estudantina, e que estabelece un xogo intertextual co debut narrativo de Riestra, Anatol y dos más (1996). Por estes trazos, e por algún outros, a novela podería ser considerada como exemplo dun noire posmoderno, que combina suspense e intriga. 
A narración comeza co encontro entre Dafne (camareira e ex-estudante) e Xurxo (estudante de Filoloxía), para logo seguir de perto os pasos deste e do seu amigo o Tolo, implicados en turbos negocios na Deep web. O inspector Touriñán e a comisaria Abelenda serán encargados investigar as estrañas mortes (anunciadas) de ambos e a súa relación cunha misteriosa cinta de video que introduce o tema da explotación sexual das mulleres e leva a intriga narrativa á década de 80 , e conduce as súas sospeitas cara á implicación nos crimes dos ricos e poderosos, da curia compostelá que sempre gobernou, na sombra, a cidade. A novela conclúe de forma aberta, colocando novas incertezas sobre o que realmente sucedeu (ou vai suceder) e obrigando o/a lector/a a construír as súas propias hipóteses.

Noire Compostela contén non poucos trazos paródicos e doses de humor, especialmente evidentes na caracterización dos personaxes: Dafne, moderna feiticeira, é unha revisión irónica e aggiornada á cidade estudantil dos estereotipos da femme fatale; na comisaria Abelenda póñense de manifesto os xa tópicos da cotidianeidade familiar das modernas mulleres policías; o inspector Touriñán é descrito inicialmente como un probábel porteiro de discoteca ou monitor de ximnasio etc. Canónigos da Catedral, directores de xornal, donas de pensións, porteiras completan a galería de personaxes que desfilan polas páxinas da novela, compondo un retrato negro da sociedade compostelá.

Ironía e reflexión metaliteraria son dous elementos relevantes na obra, que coloca desde o inicio unha definición dos roles de xénero, para advertir da inversión dos estereotipos do noir: "En historias coma esta as rapazas son duras coma a pedra e os mozos son mórbidos e sensíbeis coma as flores" (Riestra 2016: 8-9). Rapazas como a eventual e fantasmagórica vítima que transmuta en posíbel asasina, xogando máis unha vez con códigos e estereotipos do xénero criminal e do fantástico. Ou como a propia comisaria Abelenda, a responsábel da investigación, ou a forense con xenio que acode aos escenarios do crime.

Noire Compostela responde en certa medida ao concepto de flexinarratividade definido para os estudos audiovisuais por Nelson: final aberto, ambigüidade, reparto coral, axilidade narrativa, hipertextualidade, redefinición dos roles de autor(a)/lector(a), metaficcionalidade, intertextualidade, multimedia, complexidade do heroe etc.

As referencias intertextuais e hipertextuais van alén do ámbito literario, remiten á cultura de masas (música, cinema e televisión) e son utilizadas para caracterizar os personaxes xeracionalmente e opor os dous planos temporais en que se move a novela: o presente e a década de 80, co ano 1983 como núcleo de estraños sucesos apenas aludidos, co pano de fondo de ritos de maxia negra, do imperio das drogas e dunha corrupción inconcreta e xeral que alcanza a cerna da cidade.

O final da novela, co inspector inspector Touriñán vomitando despois de descubrir na frigorífico da casa de Dafne a cabeza cortada do seu amigo e compañeiro Paco, deixa a narración aberta e incerta.

Noire Compostela constitúe un achegamento paródico, irónico e híbrido que xoga cos estereotipos, vellos e novos, do xénero criminal para construír unha proposta innovadora radical e orixinal. 


\section{A modo de conclusión provisoria}

As narracións criminais das autoras galegas van da parodia da novela negra clásica na obra de Laura Caveiro ao xogo irónico cos códigos do novo noire da obra de Blanca Riestra, pasando pola homenaxe aos clásicos da novela de intriga (Sete caveiras), o thriller de acción ( $O$ faro escuro) ou a indagación psicolóxica no tipo do falso culpábel (Matei un home).

As autoras contempladas neste traballo renovan a tradición da narrativa criminal galega utilizando diversos mecanismos: unhas subverten os seus códigos xenéricos - Caveiro a través da parodia, Riestra a través da deconstrución irónica-; outras redefínenos en chave femenina -Gallego incorporando unha investigadora como protagonista, López Sández feminizando os seus estereotipos.

Consecuentemente, as súas propostas narrativas van incorporar novos modelos de figuras femeninas: da presenza das mulleres en roles secundarios ou como vítimas, pasamos ao protagonismo, nas obras da década actual, de personaxes con axencia (investigadoras, xornalistas e policías), responsábeis de investigacións que non sempre se resolven de forma convencional e pechada, que deixan finais abertos (Noire Compostela) e culpábeis sen castigo (Sete caveiras). Esta redefinición de modelos femeninos non obvia o achegamento á figura da criminal, presente en Noire Compostela.

As aproximacións aos culpábeis foxen do estereotipo da maldade absoluta: son vítimas, seres fráxiles que actúan como criminais movidos por un impulso traumático ou pola culpa, que procuran a redención a través do crime (Sete caveiras, O faro escuro) ou do amor (Matei un home).

Nas tramas narrativas surxen as diversas formas de violencia contra as mulleres: a vítima pode selo casualmente (Matei un home), mais tamén ser castigada por non responder aos estereotipos da feminidade ( $O$ faro escuro); e nas orixes da investigacións encontramos diversas formas de violencia e abuso sexual, incluíndo o asasinato (Sete caveiras, O faro escuro, Noire Compostela).

En suma, o corpus analizado mostra a contribución das autoras á narrativa criminal e como o cultivo da narrativa de xénero forma parte da redefinición do modelo autorial das narradoras galegas na actualidade.

\section{BIBLIOGRAFÍA}

ALFAYA, An (2005): Matei un home. Santa Comba: tresCtres Editores.

COLMEIRO, José F. (1994): La novela policiaca española: teoría e historia crítica. Barcelona: Anthropos.

DOPICO, Montse (2012): "Furar na trastenda social: a novela negra como metáfora da desintegración". Praza Pública 9/11/2012. http://praza.gal/cultura/2632/ furar-na-trastenda-social-a-novela-negra-como-metafora-da-desintegracion/. [Último acceso: 10/2/2019].

GALLEGO ABAD, Elena (2014): Sete Caveiras. Vigo: Xerais.

GASPAR, Silvia (1994): "Dez anos de narrativa negra galega (cen anos de cine)", Anuario de Estudios Literarios Galegos 1994: 111-126. 
GONZÁLEZ FERNÁNDEZ, Helena (2009): Género y nación. La construcción de un espacio literario. Barcelona: Icaria.

GONZÁleZ GÓMEZ, Xesús (2002): A novela policial. Santiago de Compostela: Laiovento.

GONZÁLEZ-MILLÁN, Xoán (1994): Literatura e sociedade en Galicia (1975-1990). Vigo: Xerais.

(1996): A narrativa galega actual (1975-1984). Vigo: Xerais.

LAMA, Ma Xesús (2015): "La parodia de la figura tradicional del detective en la novela negra de Laura Caveiro". (Elena Losada Soler y Katarzyna Paskiewicz, eds.), Tras la pista. Narrativa criminal escrita por mujeres. Barcelona: Icaria, 161-182.

LÓPEZ SÁNDEZ, María (2015): O faro escuro. Vigo: Galaxia.

LOSADA, Elena (2015): "Matar con un lápiz. La novela criminal escrita por mujeres", Lectora 21: 9-14. DOI: 10.1344/105.000002458.

MUNCE = Losada, Elena (dir.): Mujeres y novela criminal en España desde 1975. http:// www.ub.edu/munce/. Último acceso: 1/3/2019.

RESINA, Joan Ramon (1997): El cadáver en la cocina. La novela criminal en la cultura del desencanto. Barcelona: Anthropos.

RIESTRA, Blanca (2016): Noire Compostela. Vigo: Galaxia.

VILAVEDRA, Dolores (2010): A narrativa galega na fin de século. Unha ollada crítica dende 2010. Vigo: Galaxia.

\section{PERFIL ACADÉMICO-PROFESIONAL}

Teresa López é profesora titular de Filoloxías Galega e Portuguesa na Universidade da Coruña.

Foi decana da Facultade de Filoloxía (2005-2013) e desde 2017 é directora do Departamento de Letras da súa universidade.

O seu traballo de investigación está centrado na literatura galega contemporánea. Entre as súas publicacións, destacan as monografías Névoas de antano. Ecos dos cancioneiros galego-portugueses na Galiza do século XIX (1991) -I Premio de Investigación Lingüística e Literaria Carvalho Calero-, O neotrobadorismo (1997), Sementeira de ronseis. Cinco poetas da vangarda (2000) e as edicións de Rua 26. Diálogo limiar (1996) de Álvaro Cunqueiro, A costureira d'aldea (2006) de Manuel Lugrís Freire e, en colaboración, d'O frade das dúas almas (2010) de Xosé Tobío Mayo, xunto con numerosos artigos en revistas e volumes colectivos.

Foi investigadora principal do proxecto "Cronoloxía da literatura galega contemporánea (1801-1900)" (FFI2012-37891) financiado polo Ministerio de Economía e Competitividade.

Fecha de recepción: 16/05/2019

Fecha de aceptación: 30/05/2019 